\begin{tabular}{|l|l|l|}
\hline Received : Agustus 2019 & Accepted : September 2019 & Published : Oktober 2019 \\
\hline
\end{tabular}

\title{
Tingkat Penyerapan Suara Material Bulu Ayam Denganperekat Bubuk Sebagai Pengisi Dinding Akustik
}

\author{
S Haisah ${ }^{1^{*}}$, M Muhrim T. $^{2}$ \\ 1,2 Jurusan Teknik Arsitektur, Fakultas Teknik, Universitas Ichsan Gorontalo \\ *haisah79@gmail.com
}

\begin{abstract}
The use of acoustic material must be undertaken in a prudent hum that based on the time required to the appropriate function space. Basically all materials are able to absorb Energy but the amount of the energy absorbed is different for each material. The Noise that absorbed by a layer of absorbent some converted into heat, but the majority is transmitted to the other side of the layer, unless if the transmission is confined by a barrier that heavy and impermeable. All absorbent materials porous beneficial to absorb high noise frequency. The materials that can be used as a absorbent are materials that have Coefficient of absorption above 0,3. This research is expected to obtain an alternative sound absorbent material that can be applied directly as filler in a room, acoustic wall an environmentally friendly and provided with information level sound absorption of the material so that will Enrich reference in science in areas like architecture especially renewable acoustic material. Methods used to this research are method that quantitative focuses more on the measurement of objectively. The measurement of sample using impedance tube with two microphones type 4206, where the sample made by adding adhesive powder in order to compress material chicken feathers so it is no longer need bundle when applied on the wall. The sample used has size thickness $2,5 \mathrm{~cm}, 5 \mathrm{~cm}$ and $7,5 \mathrm{~cm}$ with a diameter of $10 \mathrm{~cm}$ adapted to the diameter of impedance tube. The results of research the material is can become immaterial acoustics which can be applied on the wall, acoustic given the material it has a fairly high absorption coefficient in various stages the frequency to the thickness of different samples, where is the coefficients which reached its highest 0,95.
\end{abstract}

Keywords: Acoustics Wall, Chicken Feathers, Adhesive Powder.

\begin{abstract}
Abstrak
Penggunaan material akustik harus dilakukan secara bijak berdasarkan waktu dengung yang disyaratkan untuk setiap ruang sesuai fungsi ruangnya. Pada dasarnya semua bahan dapat menyerap energi suara, namun besarnya energi yang diserap berbeda-beda untuk tiap bahan. Energi bunyi yang diserap oleh lapisan penyerap sebagian diubah menjadi panas, tetapi sebagian besar ditransmisikan ke sisi lain lapisan tersebut, kecuali bila transmisi tadi dihalangi oleh penghalang yang berat dan kedap. Penyerap yang terbuat dari material berpori bermanfaat untuk menyerap bunyi pada frekuwensi tinggi. Bahan material yang dapat dijadikan sebagai bahan penyerap bunyi adalah bahan yang mempunyai nilai koefisien absorbsinya di atas 0,3.Penelitian ini diharapkan dapat diperoleh suatu material alternatif penyerap suara yang dapat diaplikasikan secara langsung sebagai pengisi dinding akustik dalam ruangan, yang ramah lingkungan dan dilengkapi dengan informasi tinggkat penyerapan suara dari material tersebut sehingga akan menambah referensi baru dalam ilmu pengetahuan dibidang arsitektur khususnya material akustik yang terbarukan. Metode yang digunakan pada penelitian ini adalah metode kuantitatif yang lebih menekankan pada pengukuran secara objektif. Pengukuran sampel menggunakan tabung impedansi dengan dua mikrofon type 4206, dimana sampel penelitian dibuat dengan menambahkan perekat bubuk untuk memadatkan material bulu ayam sehingga tidak lagi membutuhkan kemasan saat diaplikasikan pada dinding. Sampel yang digunakan memiliki ukuran ketebalan 2,5 cm, $5 \mathrm{~cm}$ dan $7,5 \mathrm{~cm}$, dengan diameter $10 \mathrm{~cm}$ yang disesuaikan dengan diameter tabung impedansi. Berdasarkan hasil penelitian material ini sudah dapat menjadi material akustik yang dapat diaplikasikan pada dinding akustik, mengingat material ini memiliki koefisien absorbsi yang cukup tinggi dalam berbagai tingkat frekuensi pada ketebalan sampel yang berbeda, dimana koefisien tertingginya yang mencapai 0,95 .
\end{abstract}

Kata kunci: Dinding Akustik, Bulu Ayam, Perekat Bubuk 


\section{Pendahuluan}

Pengendalian kualitas bunyi dalam bangunan dapat dilakukan dengan mendesain suatu ruang berdasarkan standar waktu dengung yang disyaratkan sesuai dengan peruntukannya, dimana waktu dengung tersebut dapat dipengaruhi oleh material yang digunakan. Material pengendali kualitas bunyi disebut juga material akustik, dimana material akusti dapat berupa material lantai dinding langit-langit atau plafond. Material akustik dapat berupa material pengisi dan material yang dapat langsung diaplikasikan pada permukaan bidang dalam bangunan. Menurut Doelle, bahan material yang dapat dijadikan sebagai bahan penyerap bunyi adalah bahan yang mempunyai nilai koefisien absorbsinya di atas $0,3[1]$.

Dinding akustik yang berfungsi sebagai penyerap suara dapat berupa dinding padat dimana material dindingnya dapat langsung menjadi penyerap suara, ataupun dapat berupa dinding berongga yang didalamnya dapat diisi dengan material penyerap suara. Pada penelitian ini material akustik yang dibuat adalah material sebagai pengisi dinding, dimana material ini berbahan dasar bulu ayam yang dipadatkan dengan menggunakan perekat bubuk. Penelitian menggunakan material bulu ayam sebegai pengisi dinding sebelumnya telah dilakukan oleh Haisah dengan judul Koefisien Absorpsi Limbah Bulu Ayam Pengisi Panel Dinding Akustik [2], namun pada penelitian tersebut material bulu ayam yang diuji tidak menggunakan perekat.

Material bulu ayam merupakan material yang sudah menarik perhatian beberapa peneliti sebelumnya yang diluar bidang akustik, diantaranya dilakukan oleh Arifin dengan judul Pemanfaatan Limbah Bulu Ayam Potong Metode Pengukusan Untuk Bahan Ransum Ayam Potong [3], Janari dngan judul Pembuatan Prototope Genteng Komposit bulu Ayam [4], Acda dengan judul Limbah Bulu Ayam Sebagai Penguatan Dalam Sementerikat Komposit[5], dan oleh Budianto dengan judul Desain Bioball Berbahan Komposit Bulu-resin Polyester [6].

Sementara penelitian dengan material bulu ayam yang berhubungan dengan dibidang arsitektur khususnya material akustik telah dilakukan oleh Haisah dengan judul Koefisien Absorpsi Limbah Bulu Ayam Pengisi Panel Dinding Akustik, dimana sampel dibuat dengan mengemas bulu ayam sehingga berbentuk silinder sebelum diuji[2], dimana penelitian tersebut dilakukan untuk mengetahui karakteristik akustik dari bulu ayam itu sendiri yang tanpa bahan campuran, agar diketahui tingkat kelayakannya untuk menjadi material pengisi dinding akustik, Ansarullah juga telah melakukan penelitian dengan judul Pemanfaatan Limbah Bulu Ayam.

Sebagai Material Pembuat Panel Akustik [7], dimana material pada penelitian tersebut adalah bulu ayam yang telah dicacah dan menggunakan lem fox sehingga membentuk panel akustik. Sementara pada penelitian kali ini material akustik sebagai pengisi yang akan dibuat dengan menambahkan bahan perekat bubuk untuk memadatkan material bulu ayam sehingga tidak lagi membutuhkan kemasan, dan akan memudahkan saat diaplikasikan sebagai bahan pengisi dinding akustik.

Perekat merupakan bahan tambahan untuk menyambung, menggabungkan ataupun merapatkan benda maupun partikel kecil. Perekat dapat berbentuk cair, pasta maupun bubuk. Kekuatan perekat tergantung formula dari bahan perekat tersebut. Perekat dapat dibuat dari bahan alami maupun bahan sitetis. Perekat sintetis banyak digunakan dalam penelitian, diantaranya adalah pembuatan papan partikel yang menggunakan perekat Urea Formaldehyda (UF) atau Polivynil Asetat (PVAc). Berdasarkan penelitian yang dilakukan Hamdi [8], penggunaan perekat yang berbeda menghasilkan nilai kerapatan papan partikel akan berbeda kerena perbedaan komposisi bahan perekat yang digunakan, perekat UF berbentuk cairan sedangkan 
perekat PVAc tidak menggunakan air sebagai pelarut tetapi sudah berbentuk pasta.

Penelitian yang berhubungan dengan material akustik yang dibuat menggunakan perekat salah satunya dilakukan oleh Indrawati [9], dengan judul Koefisien Penyerapan Bunyi Bahan Akustik Dari Pelepah Pisang Dengan Kerapatan Yang berbeda, dimana pada penelitian tersebut menggunakan perekat alami dari kanji. Sementara, pada penelitian ini akan digunakan perekat sintetis yang berbentuk bubuk untuk memudahkan dalam pengaplikasiannya pada bahan dasar yang berupa bulu ayam.

\section{Metoda Penelitian}

\subsection{Teknik Pengumpulan Data}

Ada dua jenis teknik pengumpulan data yang digunakan dalam penelitian ini, yaitu:

a. Data primer yaitu data yang diperoleh dari pengukuran sampel yang menggunakan tabung impedansi, dimana sampel dibuat dengan 3 fariasi ketebalan dan diameter $10 \mathrm{~cm}$. Untuk setiap fariasi sampel dibuat sebanyak 5 buah.

b. Data sekunder yaitu data yang diperoleh dengan melakukan pengamatan dan pencatatan tentang informasi-informasi yang berhubungan material dan alat yang digunakan pada penelitian ini.

\subsection{Teknik Analisis Data}

Teknik analisis data dilakukan dengan membandingkan kurva yang terbentuk pada pengujian material akustik bulu ayam dengan 3 variasi ketebalan yaitu $2,5 \mathrm{~cm}, 5 \mathrm{~cm}$ dan 7,5 $\mathrm{cm}$, dengan kerapatan massa $350 \mathrm{~kg} / \mathrm{m}^{3}$. Pengujian juga dilakukan dengan menyusun sampel material bulu ayam yang dilapis dengan gipsum akustik berlubang.

\section{Hasil Penelitian}

\subsection{Proses Pembuatan Sampel}

Proses pembuatan sampel penelitian ini dimulai dari persiapan material dasar yang berupa bulu ayam, dimana bulu ayam yang digunakan yakni seluruh bulu ayam kecuali bulu ekor dan sayap karena pada bagian bulu sayap dan ekor tulang bulu terlalu besar dan kaku. Bulu ayam ini kemudian dicuci menggunakan sabun cair yakni sunlight untuk menghilangkan bau anyir, lalu bulu direndam selama 12 jam menggunakan cairan pemutih baiclin yang berfungsi sebagai disinfektan untuk membunuh mikroorganisme yang dapat merusak yang ada pada bulu ayam. Selanjutnya bulu ayam dikeringgan dibawah sinar matahari selama 3 hari. Selain bulu ayam bahan lain yang digunakan pada penelitian ini adalah perekat bubuk yang berfungsi untuk merapatkan bulu ayam sehingga tidak perlu lagi menggunakan kemasan berupa jaring nyamuk seperti penelitian sebelumnya.

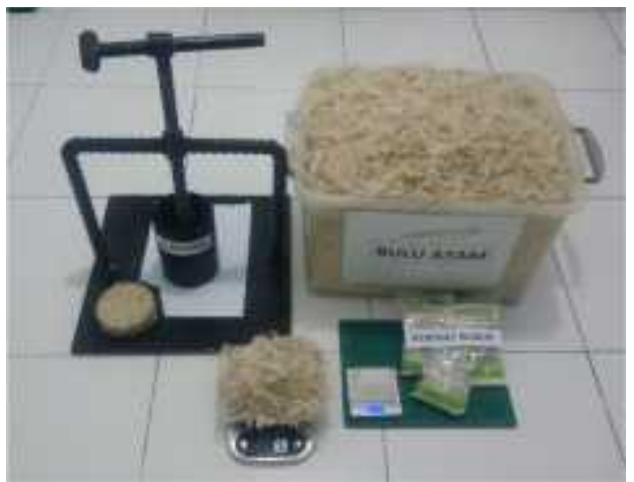

Gambar 1. Bahan dan Alat Pembuatan Sampel Material Akustik Bulu Ayam

Proses selanjutnya adalah menimbang bahan dasar yang ukurannya disesuaikan dengan kerapatan sampel yang dibuat. Kemudian bahan ini dicampus sambal disemprot dengan air agar perekat dapat berfungsi baik, selanjutnya bahan yang telah tercampur rata dicetak menggunakan alat pres dengan ketebalan yang telah ditentukan.

\subsection{Proses Pengujian Sampel}

Pengujian sampel dilakukan pada Acoustic Workshop, Building Science Laboratory di Universitas Hasanuddin Gowa. Pengukuran sampel ini menggunakan tabung impedansi type 4206 yang dapat merekam gelombang bunyi untuk mengukur tingkat penyerapan suara material pada rentang frekuensi $100 \mathrm{~Hz}-1,6 \mathrm{KHz}$. Penelitian ini juga menggunakan softrware PULSE Labshop versi 16.1 dan program Microsoft office excel untuk mengolah data dalam bentuk kurva nilai absorbs suara material akustik bulu ayam.

Pengujian sampel diawali dengan memberi nama untuk setiap variasi sampel. Nama sampel 
dibuat untuk memudahkan mengenali karakteristi dari sampel tersebut. Variasi sampel yang diuji dapat dilihat pada tabel 1 .

Pengujian sampel dilakukan satu persatu dengan memasukkan sampel pada tabung impedansi yang berukuran $10 \mathrm{~cm}$, yang kemudian data hasil pengukuran dikumpulkan lalu diolah menggunakan program Microsoft office excel yang selanjutnya ditampilkan dalam bentuk kurva.

Tabel 1. Variasi Sampel Penelitian

\begin{tabular}{|c|c|}
\hline Nama Sampel & Karakteristik Sampel \\
\hline $\mathrm{BA}+\mathrm{P} .350 .2,5$ & $\begin{array}{l}\text { Material bulu ayam dengan } \\
\text { penggunaan perekat bubuk, } \\
\text { dengan kerapatan massa } \\
350 \mathrm{~kg} / \mathrm{M}^{3} \text {, dan ketebalan } 2,5 \mathrm{~cm}\end{array}$ \\
\hline $\mathrm{BA}+\mathrm{P} .350 .5,0$ & $\begin{array}{l}\text { Material bulu ayam dengan } \\
\text { penggunaan perekat bubuk, } \\
\text { dengan kerapatan massa } \\
350 \mathrm{~kg} / \mathrm{M}^{3} \text {, dan ketebalan } 5,0 \mathrm{~cm}\end{array}$ \\
\hline $\mathrm{BA}+\mathrm{P} .350 .7,5$ & $\begin{array}{l}\text { Material bulu ayam dengan } \\
\text { penggunaan perekat bubuk, } \\
\text { dengan kerapatan massa } \\
350 \mathrm{~kg} / \mathrm{M}^{3} \text {, dan ketebalan } 7,5 \mathrm{~cm}\end{array}$ \\
\hline
\end{tabular}

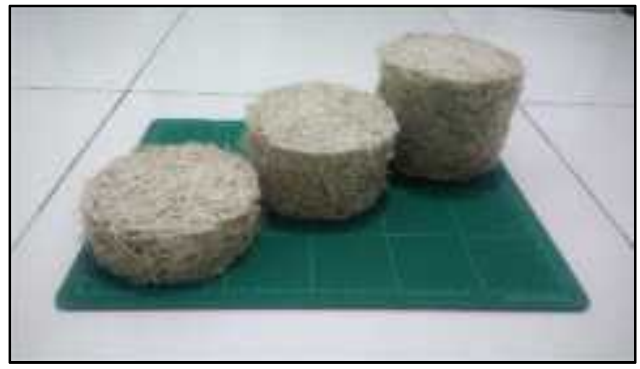

Gambar 1. Varian sampel 2,5cm, 5,0cm, 7,5cm

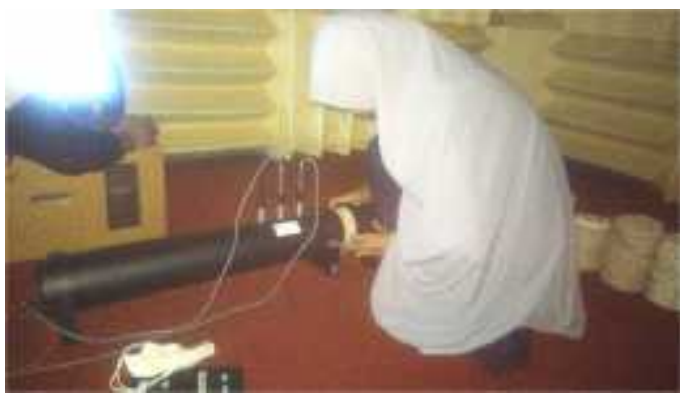

Gambar 2. Proses Pengujian Sampel Material Akustik Bulu Ayam

\subsection{Tingkat penyerapan suara matrial} BA+P.350.2,5

Dari kurva hasil pengukuran koefisien absorbsi material akustik bulu ayam denggan penggunaan perekat bubuk untuk sampel dengan ketebalan 2,5cm menunjukkan adanya peningkatan koefisien absorbsi untuk rentang pengukuran $100 \mathrm{~Hz}-1,6 \mathrm{KHz}$, dimana koefisien absorbsi terus miningkat dan mencapai nilai tertinggi berada pada frekuensi $950 \mathrm{~Hz}$ dengan tingkat penyerapan 0,95. Pada frekuensi selanjutnya koefisien absorbsi turun hingga mencapai nilai terendah 0,71 pada frekuensi $1530 \mathrm{~Hz}$, kemudian kembali naik untuk frekuensi selanjutnya.

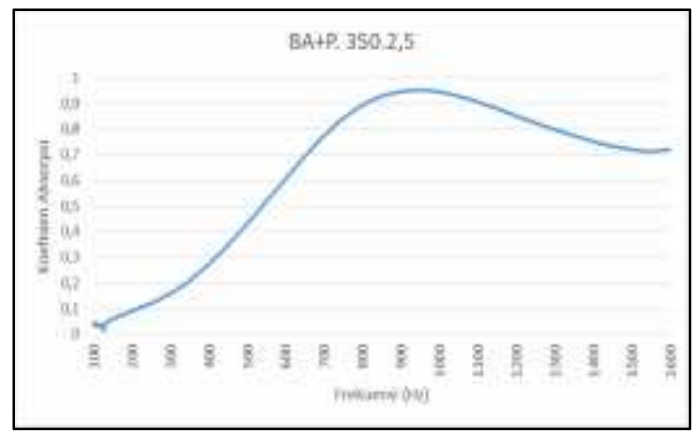

Gambar 3. Kurva BA+P.350.2,5

\subsection{Tingkat penyerapan suara matrial BA+P.350.5,0}

Untuk hasil pengukuran material dengan ketebalan sampel $5 \mathrm{~cm}$ diperoleh koefosien absorbs tertinggi berada pada frekuensi $450 \mathrm{~Hz}$ dengan tingkat penyerapan 0,7 , selanjutnya kemampuan penyerapannya turun mencapai 0,58 pada frekuensi $850 \mathrm{~Hz}$ dan kembali naik hingga pada frekuensi $1600 \mathrm{~Hz}$ koefisien absorbsinya mencapai 0,77 .

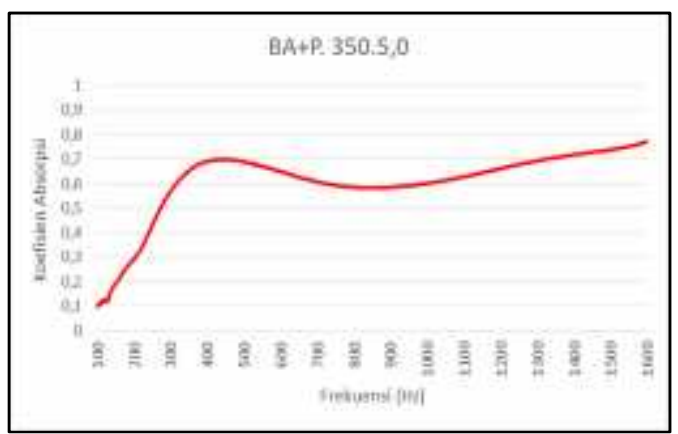

Gambar 1. Kurva BA+P.350.5,0 
3.5. Tingkat penyerapan suara matrial BA+P.350.7,5

Pengujian material dengan ketebalan 7,5 menghasilkan koefisien absorbsi tertinggi awal ada pada frekuensisi $300 \mathrm{~Hz}$ dengan tingkat penyerapan 0,44 , selanjutnya turun $\mathrm{m} 0,4$ pada frekuensi $450 \mathrm{~Hz}$ yang justru kebalikan dari material dengan ketebalan $5 \mathrm{~cm}$, dimana pada frekuensi $450 \mathrm{~Hz}$ adalah posisi koefisien tertinggia awal. Pada kurva menunjukkan adanya peningkatan kembali koefisien absorbs material hingga pada frekuensi $1600 \mathrm{~Hz}$ tingkat penyerapan mencapai 0,72 .

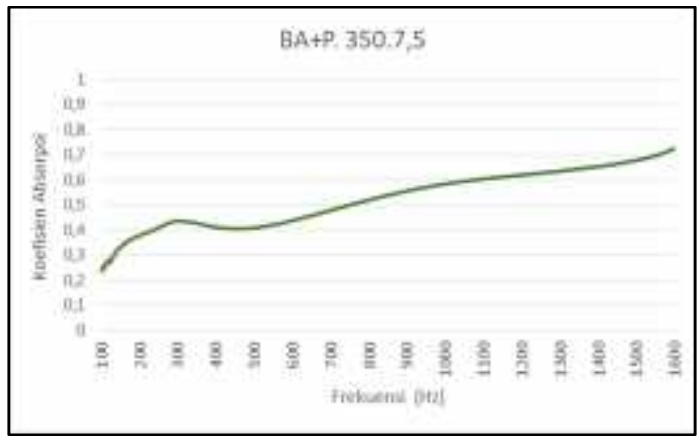

Gambar 1. Kurva BA+P.350.7,5

\section{Kesimpulan}

Berdasarkan hasil penelitian dari material akustik bulu ayam dengan penggunaan perekat bubuk, maka dapat disimpulkan bahwa material ini sudah dapat menjadi material akustik yang dapat diaplikasikan sebagai pengisi pada dinding akustik mengingat material ini memiliki koefisien absorbsi yang cukup tinggi dalam berbagai tingkat frekuensi pada ketebalan sampel yang berbeda, dimana koefisien tertingginya yang mencapai 0,95

\section{Saran}

Pada penelitian selanjutnya disarankan untuk melakukan pengujian langsung dengan pengaplikasian pada dinding suatu ruangan yang membutuhkan kontrol akustik yang baik.

\section{Daftar Pustaka}

[1] L. L. Doelle, Akustik Lingkungan, Jakarta: Erlangga, 1993.

[2] S. Haisah, Koefisien Absorpsi Limbah Bulu Ayam Pengisi Panel Dinding Akustik (tesis), Makassar: Universitas Hasanuddin., 2015.

[3] T. Arifin, "Pemanfaatan Limbah Bulu Ayam Potong Metode Pengukusan Untuk Bahan Ransum Ayam Potong (Tesis)," USU Institutional Repository, Medan, 2008.

[4] D. Janari, "Pembuatan Prototipe Genteng Komposit Bulu Ayam (skripsi)," Jurusan Teknik Mesin, FTI - UII, 2010.

[5] M. N. Acda, " Waste Chicken Feather as Reinforcement in Cement Bonded Composites," Philippine Journal of Science., vol. 2, p. 161 - 166., 2010.

[6] R. Budianto, "Desain Bioball Berbahan Komposit Bulu AyamResin Polyester: Sifat Material, Karakteristik Bentuk dan Karakteristik Hidraulik (tesis)," Universitas Gadjah Mada , Yogyakarta, 2013.

[7] Ansarullah, "Pemanfaatan Limbah Bulu Ayam Sebagai Material Pembuat Panel Akustik," in Simposium Nasional RAPI $X V$, FT UMS, 2016.

[8] H. Saibatul, "Penggunaan Jenis Perekat Terhadap Sifat Fisis Dan Mekanis Papan," Jurnal Riset Industri Hasil Hutan, vol. 2, 2010.

[9] E. Indrawati, "Koefisien Penyerapan Bunyi Bahan Akustik Dari Pelepah Pisang Dengan Kerapatan Yang berbeda," Jurnal Neutrino, vol. 2, no. No. 1, 2009. 